\title{
Funcionalidad familiar y abuso en adolescentes del Tercer Ciclo de la E.E.B. de la Escuela Privada Subvencionada N4178 "San Antonio de Fe y Alegría" del año 2018
}

\author{
Cecilia Amarilla Duarte ${ }^{1}$
}

\section{Resumen}

Introducción: La problemática que se observa en la Escuela Privada Subvencionada $N^{\circ} 4178$ San Antonio de Fe y Alegría donde acuden adolescentes de las zonas aledañas de bajo nivel socioeconómico y según manifestaciones de directivos, docentes, departamento de orientación y los padres de familias, varios de ellos presentan conductas agresivas, adicciones al alcohol y otras sustancias, huidas de casa, ideas suicidas, autoflagelación, por lo que no se descarta la presencia de abuso físico, psicológico, sexual o por negligencia dentro de sus familias que justifiquen las mencionadas conductas. La investigación puede ser de utilidad a la comunidad educativa, a estudiantes de psicología y puede servir como base para futuras investigaciones referentes al tema y también para otras especialidades.

Objetivo: Determinar la relación entre el nivel de la funcionalidad familiar y el abuso físico, psicológico, sexual y por negligencia en adolescentes que asisten en la Escuela Privada Subvencionada N4178 San Antonio de Fe y Alegría del año 2018.

Material y Método: Población compuesta por 60 estudiantes de ambos sexos entre 13 a 15 años del tercer ciclo de la Etapa Escolar Básica. Se trabajó con el total de la población porque todos tenían denuncias por diferentes clases de abuso en la CODENI de la zona. El tipo de investigación es cuantitativo, de nivel correlacional y su diseño fue no experimental, se abordó desde la perspectiva de la Psicología como ciencia que estudia la conducta humana. La técnica aplicada fue la entrevista, la observación y la aplicación de test. Los instrumentos utilizados son: el cuestionario de la Escala de Funcionalidad familiar (FACES-20ESP) para determinar el nivel de funcionalidad de las familias y la Escala de la Conducta Abusiva y los niveles de abuso físico, psicológico, sexual y por negligencia.

1. Universidad Tecnológica Intercontinental, Paraguay.

E-mail: cecilduart62@gmail.com

DOI: 10.26885/rcei.foro.2019.253

Trabajo publicado en acceso abierto bajo Licencia Creative Commons. 
Resultados: Los resultados de la medición de la variable Funcionalidad Familiar muestran que de los 60 adolescentes, 5 presentan puntajes que lo ubican en el nivel bajo de funcionalidad familiar representados por el 8,3\%; mientras que 33 adolescentes que representa al $55,0 \%$ de la muestra presentan puntajes que los ubica en el nivel medio de funcionalidad familiar; seguidos de 22 adolescentes que representa el $36,7 \%$ de la totalidad de los datos con puntajes que lo ubican en un alto nivel de funcionalidad familiar. En cuanto al nivel de abuso de la muestra, 2 adolescentes que representa al 3,3\% de los encuestados presentan puntajes que lo ubican en el nivel leve, mientras que 56 adolescentes que representa al 93,3\%, presentan puntajes que los sitúan en el nivel moderado, seguidos de 2 adolescentes que representa al 3,3\% de la totalidad de los datos que lo ubican en nivel grave de conducta abusiva.

Conclusión: La relación entre las variables refleja la existencia de la relación, pero de carácter muy débil entre ambas variables que es del $34 \%$ y hace referencia a una relación de manera indirecta o inversa entre las variables analizadas, esto indica que, si aumenta el puntaje de funcionalidad familiar disminuiría los puntajes de la conducta abusiva o viceversa. Cuando existe mayor adaptabilidad, cohesión, satisfacción y comunicación asertiva, la exposición a los abusos disminuye en el sistema.

Palabras clave: funcionalidad familiar, abuso, adolescente.

\section{RefEREnCias}

Corsi, J. (1994). Una mirada abarcativa sobre el problema de la violencia familiar. Buenos Aires, Argentina: Paidós.

Echeburrúa, E., \& Redondo, S. (2010). Abuso sexual en la infancia: víctimas y agresores. Barcelona, España: Ariel.

Huelva López-Soler, C. (2008). El trauma complejo en infancia y adolescencia maltratada. Revista de Psicopatología y Psicología Clínica, 13(3), 159-174.

Huelva López-Soler, C. (2008). El trauma complejo en infancia y adolescencia maltratada. Revista de Psicopatología y Psicología Clínica, 13(3), 159-174.

Olson, D. (1985). Family adaptability and cohesion evaluation Scales (FACES III). Minnesota, Estados Unidos: Family Social Science. 